\title{
QUANTIFICAÇÃO DE BACTÉRIAS E FUNGOS EM SOLOS DE CULTIVO CONVENCIONAL E AGROECOLÓGICO EM FRONTEIRA/MG
}

\author{
PINHEIRO, Andreza de Souza ${ }^{1}$ \\ MARTINS, Eduardo da Silva ${ }^{2}$ \\ MARTINS, Heytor Lemos ${ }^{3}$
}

RESUMO: A quantidade de microrganismos pode variar de acordo com as condições de crescimento a que eles estão expostos. Neste sentido, o objetivo deste estudo foi avaliar a microbiota de solos em três condições distintas: sob manejo convencional, sem cultivo (como controle) e com cultivo agroecológico, em duas propriedades rurais vizinhas, no município de Fronteira/MG. Foram realizadas seis coletas quinzenais, em cinco pontos (dois agroecológicos, um sem cultivo e dois convencionais), entre os meses de setembro a dezembro de 2018, totalizando 30 amostras. As amostras de solo foram coletadas na profundidade de $20 \mathrm{~cm}$, sendo feitas análises da quantidade de bactérias e fungos. Os resultados mostraram que as maiores contagens de bactérias e fungos foram obtidas nos pontos agroecológicos e também no ponto convencional com cultivo de cana de açúcar (onde há manutenção da palha de cana e inserção de torta de filtro). As contagens mais baixas foram observadas no solo sem cultivo e no solo com cultivo de abacaxi. Os resultados obtidos reforçam a importância de boas práticas de manejo no solo, para o crescimento microbiano.

Palavras-chave: Microrganismos; Bioindicadores; Manejo do solo.

SUMMARY: The number of microorganisms may vary according to the growth conditions these microorganisms are exposed. In this respect, this study aimed to evaluate the microbiota from soils in three different conditions: under conventional management, without cultivation and with agroecological cultivation, in two neighboring farms, in the municipality of Fronteira/MG. Six biweekly samples, in five points (two agroecological, one non-cultivated and two conventional) were collected between September and December 2018. Soil samples were collected at depth of $20 \mathrm{~cm}$, and the analyses over them broached the number of bacteria and fungi. The results showed that the highest bacterial and fungus counts were obtained from the agroecological points and from the conventional point with sugarcane cultivation (in the presence of sugarcane straw and filter cake insertion), while lower counts were observed in soils without cultivation and with pineapple cultivation. In light of this, the results reinforce the importance of good soil management practices for microbial growth.

Keywords: Microorganisms; Bioindicators; Soil management.

\section{INTRODUÇÃO}

A agroecologia se constitui em formas de diversificação, tais como policulturas, circuitos, culturas de cobertura e inserção animal, para desenvolver a produção e assegurar a energia do agroecossistema de forma que impactos ambientais sejam minimizados e a produção ocorra de forma sustentável. A adoção deste sistema sustentável de produção vem aumentando consideravelmente nos últimos anos, com a demanda da sociedade por alimentos que apresentem

\footnotetext{
${ }^{1}$ Especialista em Agroecologia no Cerrado. Universidade do Estado de Minas Gerais, unidade Frutal.

${ }^{2}$ Doutor em Microbiologia Aplicada. Universidade do Estado de Minas Gerais, unidade Frutal.

${ }^{3}$ Mestrando em Ciências Ambientais. Universidade do Estado de Minas Gerais, unidade Frutal.
} 
maior qualidade e que, em seu processo produtivo, resultem em menores impactos ambientais (PENTEADO, 2012; FERREIRA et al., 2017).

A heterogeneidade biológica proporcionada pela agroecologia auxilia na manutenção da cadeia alimentar, de modo a promover o controle das espécies, por conseguinte quanto mais estabilizado estiver o ecossistema local, menores serão os problemas fitossanitários. Com uma maior população de inimigos naturais, menor será o ataque de pragas nas culturas existentes ao redor e, dessa forma, se ocorrerem mudanças no sistema agrícola corrente (transição do manejo convencional para o agroecológico) o uso dos insumos químicos será cada vez menos essencial (GLIESSMAN, 2009).

O solo não é utilizado somente como substrato para desenvolvimento de plantas (produção de alimentos), ele também é considerado um "ente" vivo, porque nele está presente uma enorme biodiversidade. Por ser um recurso natural, possui qualidade definida dentro dos limites do ecossistema e, quando preservado, garante a produtividade biológica (MELONNI et al., 2008; PARRON; GARCIA, 2015; CARDOSO e FAVERO, 2018).

O manejo intensivo do solo e a má realização deste pode ocasionar um processo de degradação que, no caso de ser reversível, precisa de um tempo maior e também de recurso para sua recuperação (CHERUBIN et al., 2015). Portanto, necessita-se de um monitoramento dos solos manejados para a preservação da qualidade e para que possibilite uma produção continuada.

Os microrganismos são essenciais para a disponibilização e fixação de nutrientes no solo. Pesquisas têm apontado que a comunidade microbiana do solo é bastante sensível às alterações provenientes das atividades agrícolas, fornecendo assim subsídios importantes para o planejamento do uso da terra e manejo do solo. Assim, por ser a parte mais viva e ativa da matéria orgânica do solo e por atuar em importantes processos bioquímicos, estudos mostram que os indicadores biológicos são mais sensíveis que os indicadores químicos e físicos para detectar com mais antecedência alterações que ocorrem no solo em função do seu uso e manejo (BUENO et al., 2018).

Diante deste contexto, o objetivo deste trabalho foi determinar a quantidade de bactérias e fungos em amostras de solo com cultivo convencional e agroecológico em duas propriedades rurais no município de Fronteira/MG, visando avaliar se os diferentes tipos de cultivo provocam variações na quantidade de microrganismos no solo.

\section{MATERIAL E MÉTODO}

\section{Área experimental}

As coletas foram realizadas na Fazenda Horta Rio Grande e em uma propriedade vizinha (Figura 1). A Horta Rio Grande está localizada no município de Fronteira na região Sudeste do 
país, na mesorregião do Triângulo Mineiro e Alto Paranaíba e Microrregião de Frutal. Possui latitude $20^{\circ} 16^{\prime} 04^{\prime \prime}$ sul, longitude $49^{\circ} 11^{\prime} 58^{\prime \prime}$ oeste e altitude de 458 metros. Localiza-se as margens do Rio Grande, e possui uma população de 16.400 habitantes numa área de $200 \mathrm{~km}^{2}$. Seus municípios limitam com Frutal/MG, Guaraci, Icém e Orindiúva, sendo os três últimos do estado de São Paulo.

Figura 1. Localização da área de estudo.

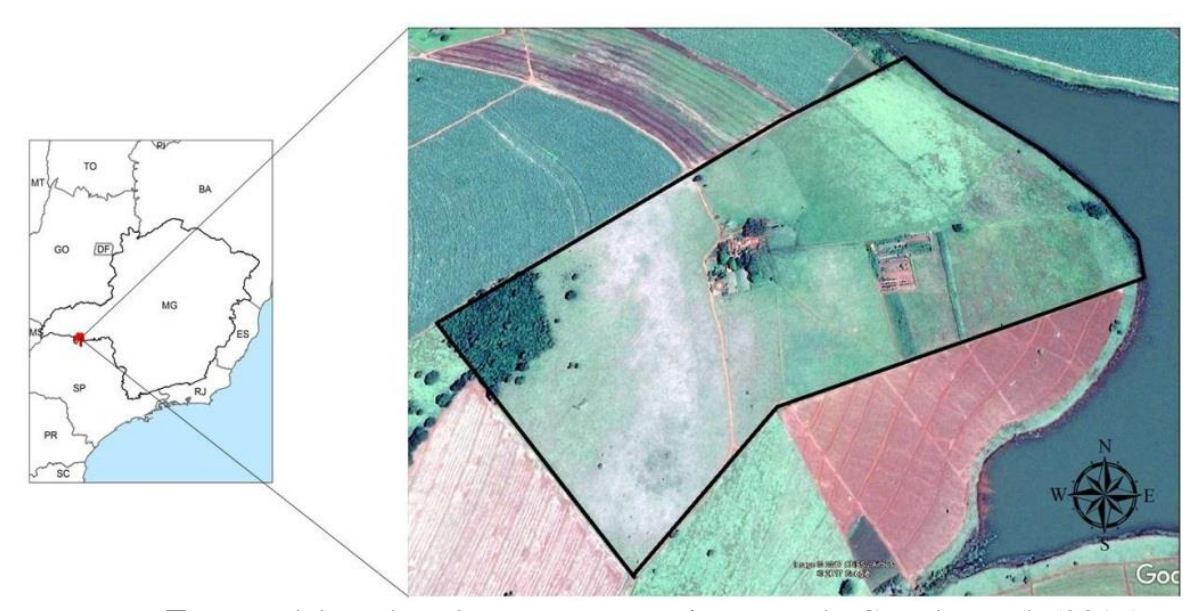

Fonte: Elaborada pelos autores, com imagens do Google Earth (2019).

As amostras de solo foram coletadas entre $11 \mathrm{~h}$ e $12 \mathrm{~h}$ em cinco pontos distintos da fazenda sendo uma distância de 50m um ponto do outro, para entender melhor os: pontos 1 e 2 com cultivo de hortaliças nos princípios da agroecologia, ponto 3 com canteiro que estava sem cultivo e assim permaneceu até sua última coleta e pontos 4 e 5 com cultivos convencionais de abacaxi e cana-deaçúcar, sendo o cultivo convencional de abacaxi feito dentro da propriedade, já o plantio de cana faz parte de uma propriedade vizinha. Os pontos de coleta estão representados na figura 2. 
Figura 2. Mapa com identificação dos pontos de coletas.

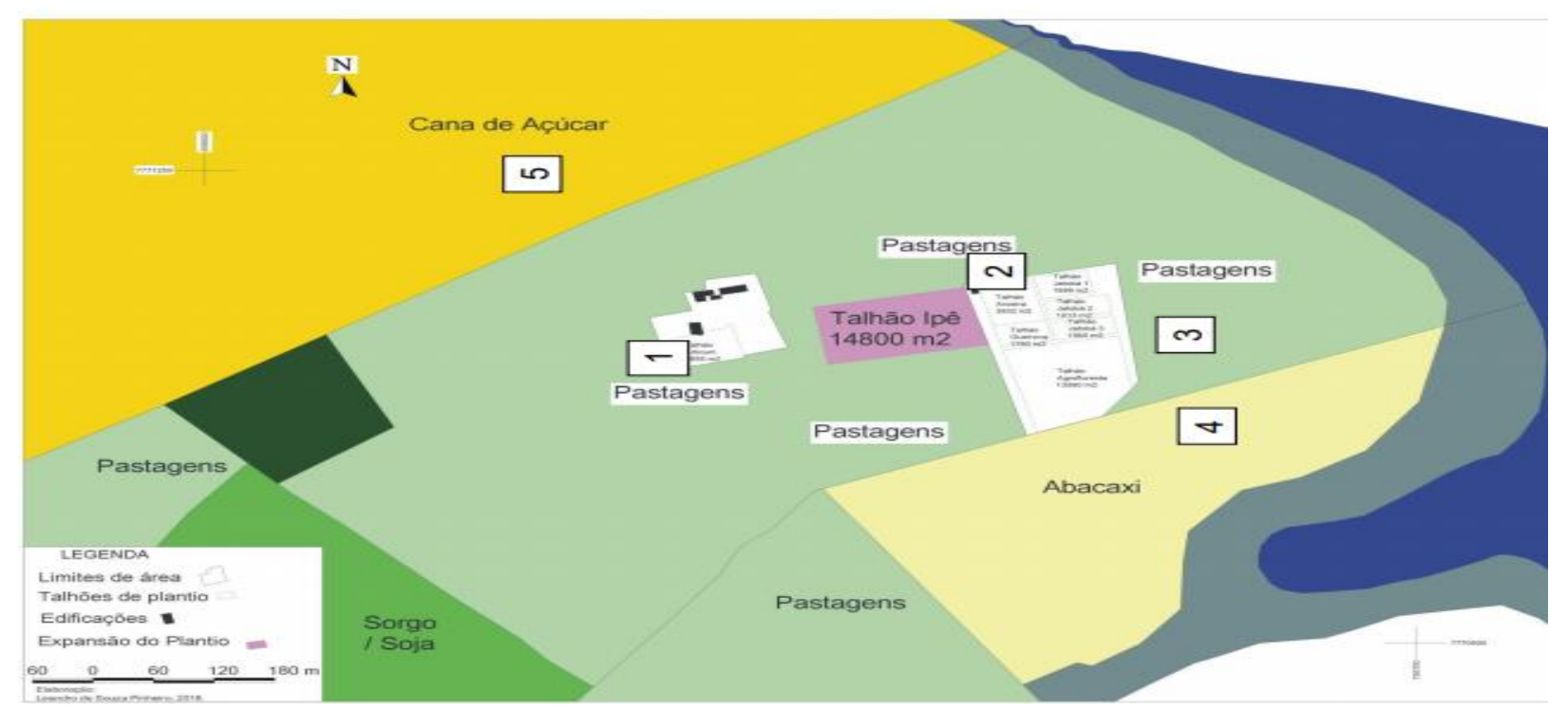

Legenda: Ponto 1 Talhão Articum Agroecológico; Ponto 2: Talhão Aroeira Agroecológico; Ponto: 3 área sem cultivo; Ponto 4: área de cultivo convencional de abacaxi. Ponto 5: área de cultivo convencional de cana-de-açúcar.

Fonte: Elaborada pelos autores.

\section{COLETA DE SOLOS}

As coletas das amostras ocorreram quinzenalmente (Setembro a Dezembro de 2018), sendo retirados $100 \mathrm{~g}$ de solo de cada área selecionada, a uma profundidade de $20 \mathrm{~cm}$. Foram realizadas 6 coletas, sendo uma amostra de cada um dos cinco pontos, totalizando assim 30 amostras. Estes solos foram armazenados em sacos plásticos, identificados e transportados para o Laboratório de Microbiologia da Universidade do Estado de Minas Gerais - UEMG, Unidade Frutal.

\section{PREPARO DOS MEIOS DE CULTURA, INOCULAÇÃO E ANÁLISES MICROBIOLÓGICAS}

Para contagem dos microrganismos foram utilizados os meios de cultura BDA (Batata Dextrose Agar - Acumedia) para identificação de bolores e leveduras e PCA (Plate Count Agar Acumedia) para crescimento de bactérias. Os meios plaqueados foram feitos em duplicatas, com diluição seriada de até $10^{-6}$, com uso de água peptonada a $0,1 \%$.

Para o preparo do solo, mediu-se 10 gramas de cada amostra de solo e diluiu-se em $90 \mathrm{~mL}$ de água peptonada $0,1 \%$ esterilizada, sendo esta a diluição $10^{-1}$. Posteriormente, levou-se essas amostras para mesa agitadora (Astral Cientifica CT-155) mantendo-as por 20 minutos com rotação de 55 RPM. Em seguida dilui-se $1 \mathrm{~mL}$ da solução em $9 \mathrm{~mL}$ de de água peptonada 0,1\%, e assim diluições sucessivas até $10^{-6}$. 
As placas (duplicatas) para a contagem dos fungos foram colocadas na estufa bacteriológica (Biopar 522LBD) a $28^{\circ} \mathrm{C}$ por 120 horas, enquanto as placas também em duplicatas utilizadas para contagem de bactérias foram incubadas em estufa (TECNAL TE-371) a $35^{\circ} \mathrm{C}$ por 48 horas. Após esse período, foram contadas as unidades formadoras de colônias de bactérias e fungos por grama de solo (UFC/g).

\section{RESULTADO E DISCUSSÃO}

Conforme pode ser observado na Figura 3, os pontos 1 e 2 (solos com cultivo agroecológico) apresentaram valores mais elevados de contagem bacteriana em quatro das seis coletas, isso pode estar relacionado ao preparo do solo, para o plantio, já que as duas áreas estavam com presença de hortaliças. A exceção ficou por conta das coletas 4 e 5, nas quais as contagens no ponto 5 (cultivo convencional, com cultura de cana-de-açúcar) apresentaram valores mais elevados que as encontradas no ponto 1 . Um dos fatores que podem estar relacionados a esta alteração é a palhada da cana que fica sobre o solo, sendo um grande protetor da inserção direta de luz solar e mantendo a umidade do sistema, já que no período de realização dessas coletas ocorreram chuvas. 
Figura 3. Contagem de bactérias em amostras de solo com cultivo convencional e agroecológico, em duas propriedades rurais de Fronteira/MG. Pontos 1 e 2: solo com cultivo agroecológico; Ponto 3: solo sem cultivo; Ponto 4: solo com cultivo convencional de abacaxi; Ponto 5: solo com cultivo convencional de cana-de-açúcar.

Coleta 1

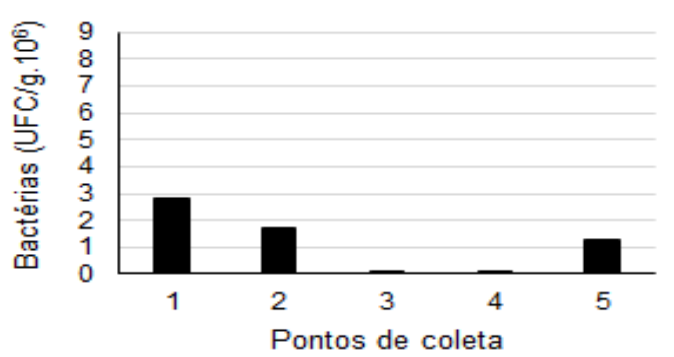

Coleta 3

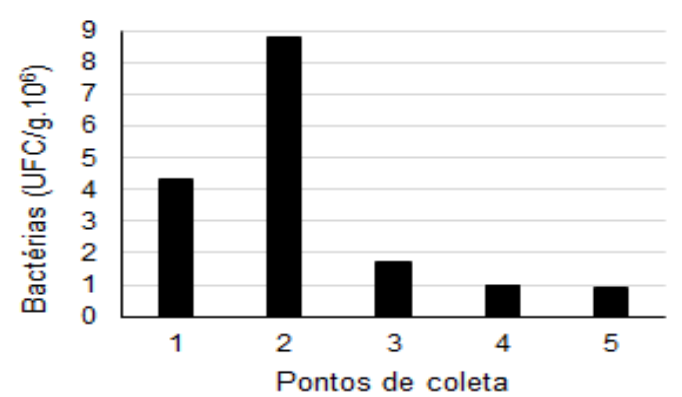

Coleta 5

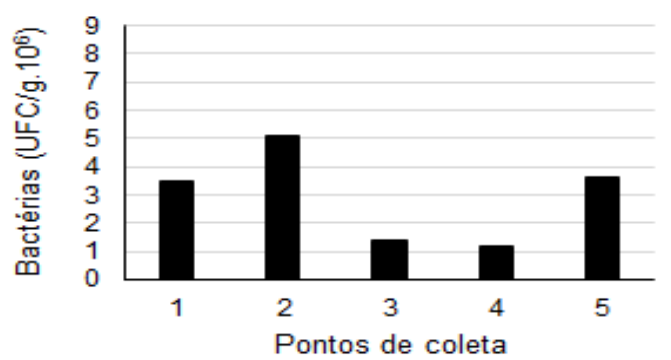

Coleta 2

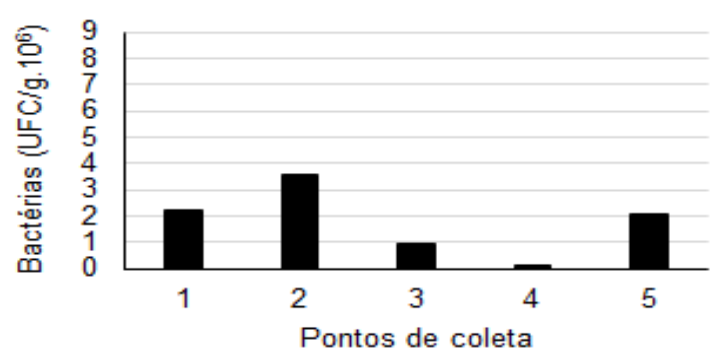

Coleta 4

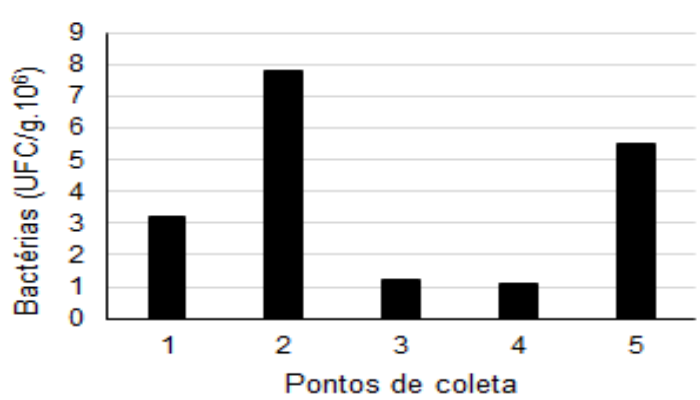

Coleta 6

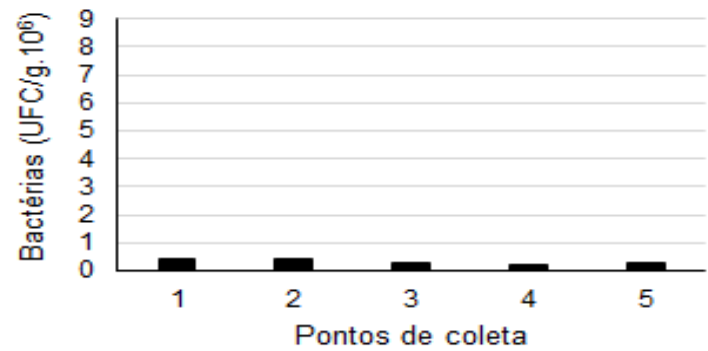

Fonte: Elaborada pelos autores

Resultados semelhantes foram encontrados em pesquisas feitas por Maluche-Baretta, Amarante e Klauberg-Filho (2007), em Santa Catarina, na comparação dos teores de C/N da biomassa microbiana em sistemas convencional e orgânico de maçãs. Um estudo feito por Rech $e t$ al. (2013), observou que o solo de vinhedos sob manejo agroecológico apresentou mais densidade de bactérias e fungos filamentosos em relação ao manejo convencional, possivelmente devido à presença de vegetação nativa e manejo com menor intensidade.

Observou-se também que as maiores contagens de bactérias foram encontradas nas coletas 3 e 4 em praticamente todos os pontos (Figura 3). Esse resultado coincide com a detecção de chuvas 
próximas ao período dessas duas coletas, o que pode ter contribuído para o aumento da população bacteriana.

Analisando os resultados obtidos em cada coleta, na coleta 1 os pontos que apresentaram maiores contagens de bactérias foram os pontos 1 e 2 (sistema agroecológico) e o ponto 5, sistema convencional, com cana-de-açúcar. Na coleta 2, estes também foram os pontos com maior quantidade. Nas coletas 3 e 4 o destaque ficou para o ponto 2, apresentando mais que o dobro de bactérias que os demais pontos. Na coleta 5 , novamente os maiores valores foram encontrados nos pontos 1, 2 e 5. Já a última coleta foi a que apresentou os menores valores de contagem bacteriana, de modo geral (Figura 3).

O resultado obtido em relação aos pontos 4 e 5 (cultivos convencionais) pode refletir a forma de manejo do solo nesses pontos. No ponto 5, quando a cana é colhida, a palha é deixada no solo, deixando assim uma cobertura vegetal importante para manutenção da umidade do solo, e que é usada como material para decomposição por microrganismos, com consequente retorno de nutrientes ao solo. Além disso, outro fato que pode contribuir para a expressiva quantidade de bactérias nesse ponto é a inserção de torta de filtro no solo, o que contribui na sua fertilização e na presença de microrganismos decompositores de matéria orgânica. Já no ponto 4 (cultura do abacaxi) isso não acontece, deixando o solo muito compactado e mais pobre em nutrientes. Além disso, nessa cultura são usados agrotóxicos que, somados a um solo sem proteção, pode ter contribuído para a menor presença de bactérias nesse estudo.

A torta de filtro é um resíduo proveniente da indústria açucareira oriundo da filtração a vácuo do lodo retido nos clarificadores. Essa é composta de resíduos solúveis e insolúveis da fase de calagem, e rico em $\mathrm{P}, \mathrm{Ca}, \mathrm{Cu}, \mathrm{Zn}$ e Fe. Pelo seu alto teor nutricional, a torta de filtro é capaz de liberar grande quantidade dos seus nutrientes no solo, além de reter água e manter a umidade do solo (SANTIAGO; ROSSETO, 2015; COSTA et al., 2016).

Com relação à contagem de fungos (bolores e leveduras), as contagens em cada ponto sofreram maiores variações em relação à cada coleta, quando comparado aos resultados obtidos para bactérias. Apenas o ponto 1 apresentou contagens mais constantes ao longo do tempo. De maneira geral, as maiores contagens também foram observadas nas coletas 3 e 4, com destaque para o ponto 5, de cultivo convencional em cultura de cana-de-açúcar (Figura 4). A maior contagem de fungos nas coletas 3 e 4 pode ter sido provocada pela presença de chuvas na fazenda nesses períodos. 
Figura 4. Contagem de fungos em amostras de solo com cultivo convencional e agroecológico, em duas propriedades rurais de Fronteira/MG. Pontos 1 e 2: solo com cultivo agroecológico; Ponto 3: solo sem cultivo; Ponto 4: solo com cultivo convencional de abacaxi; Ponto 5: solo com cultivo convencional de cana-de-açúcar.
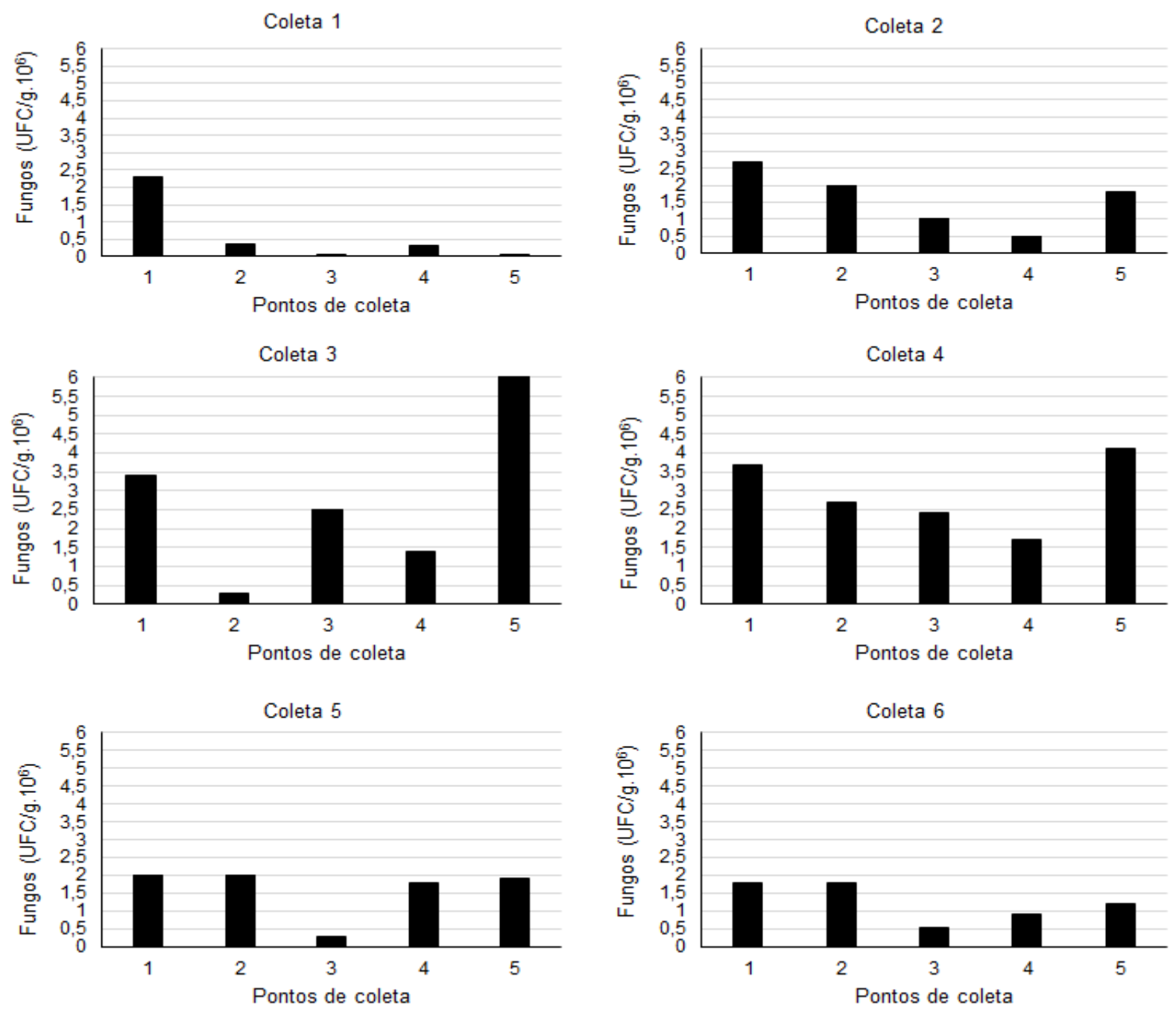

Fonte: Elaborada pelos autores

Com relação às contagens obtidas em cada coleta, observou-se que na coleta 1 , a maior quantidade de fungos foi encontrada nos solos com cultivo agroecológico. Na coleta 2, os maiores valores foram encontrados nos pontos 1 e 2 , mas contagem similar ao ponto 2 foi obtida no ponto 5 (cultivo convencional, com cana-de-açúcar). Nas coletas 3 e 4, maiores contagens de fungos foram observadas em relação aos resultados anteriores, com exceção do ponto 2 na coleta 3. Na coleta 5, valores similares foram obtidos nos pontos 1, 2, 4 e 5, com menores contagens no ponto 3 (sem cultivo). Já na coleta 6 , as maiores contagens foram obtidas nos pontos agroecológicos 1 e 2 (Figura 4). 
Assim, com relação aos pontos de cultivo convencional, observou-se resultado similar ao encontrado para bactérias, com menor quantidade de fungos no solo com cultura de abacaxi e uma quantidade expressiva no solo com cultivo de cana-de- açúcar. Esses resultados reforçam as hipóteses relacionadas à forma de manejo do solo, conforme demonstrado nos resultados de contagem de bactérias.

\section{CONCLUSÃO}

Os solos com cultivo agroecológico apresentaram contagens de bactérias e fungos superiores ao solo sem cultivo e com cultivo de abacaxi. Já o solo com cultivo convencional com cultura de cana-de-açúcar apresentou contagens expressivas de bactérias e fungos, mostrando que o seu manejo com manutenção da palhada e inserção de torta de filtro pode ter contribuído para a presença de microrganismos.

\section{REFERÊNCIAS}

BUENO, P. A. A.; OLIVEIRA, V. M. T.; GUALDI, B. L.; SILVEIA, P. H. N.; PEREIRA, R. G.; FREITAS, C. E. S.; BUENO, R. O.; SEKINE, E. S.; SCHWARCZ, K. D. Indicadores microbiológicos de qualidade do solo em recuperação de um sistema agroflorestal. Acta Braziliensis, v. 2, n. 2, p. 40-44, 2018. Disponível em:

<http://revistas.ufcg.edu.br/ActaBra/index.php/actabra/article/view/96/37> Acesso em: 16 abr. 2020 .

CARDOSO, I. M.; FÁVERO, C. Solos e agroecologia. (Coleção transição agroecológica). v. 4. Brasília, DF: Embrapa, 373 p. 2018.

CHERUBIN, M.R.; SANTI, A.L.; EITELWEIN, M.T.; AMADO, T.J.C.; SIMON, D.H. \& DAMIAN, J.M. 2015. Dimensão da malha amostral para caracterização da variabilidade espacial de fósforo e potássio em Latossolo Vermelho. Pesquisa Agropecuária Brasileira, 50, n. 2, p. 168-177. Disponível em: < http://www.scielo.br/pdf/pab/v50n2/0100-204X-pab-50-0200168.pdf> Acesso em: 12 dez. 2019.

COSTA, N. R.; LIMA, R. A.; SILVA, G. D. S.; MATOSO, A. O.; GARCIA, G. C.; ROMEIRO, E. R.; MARASCA, I.; SOUZA, D. M.; LIMA, C. G. R. Aplicação de torta de filtro no sulco de plantio sobre o desenvolvimento inicial da cana-de-açúcar. Tecnologia \& Ciência Agropecuária, João Pessoa, v.10, n.6, p.1-7, 2016. Disponível em: < https://zeoserver.pb.gov.br/gestaounificada/gu/emepa/publicacoes/revista-tcaemepa/edicoes/volume-10-2016/v-10-n-6-dezembro-2016/tca10601.pdf/view> Acesso em: 12 dez. 2019.

FERREIRA, E. P. B.; STONE, L. F.; MARTIN-DIDONET, C. C. G. População e atividade microbiana do solo em sistema agroecológico de produção. Revista Ciência Agronômica, v. 48, n. 1, p. 22-31, 2017. Disponível em: http://www.scielo.br/pdf/rca/v48n1/1806-6690-rca-4801-0022.pdf Acesso em: 08 abr 2020. Disponível em: <> Acesso em: 07 abr. 2020. 
GLIESSMAN, S.R. Agroecologia - Processos ecológicos em agricultura sustentável. 4. ed. Porto Alegre: UFRGS, 2009.

KASCHUK, G.; HUNGRIA, M. Diversity and Importance of Diazotrophic Bacteria to Agricultural Sustainability in the Tropics. In: AZEVEDO, J. L.; QUECINE, M. C. (Eds.). Diversity and Benefits of Microorganisms from the Tropics. Springer International Publishing, 269-292. 2017. Disponível em: < https://www.researchgate.net/publication/318152272_Diversity_and_Importance_of_Diazotrophi c_Bacteria_to_Agricultural_Sustainability_in_the_Tropics> Acesso em: 13 abr. 2020.

MALUCHE-BARETTA, C.R.D.; AMARANTE, C.V.T. \& KLAUBERG-FILHO, O. Análise multivariada de atributos do solo em sistemas convencional e orgânico de produção de maçãs. Pesq. Agropec. Bras., 41:1531-1539, 2006. Disponível em: <http://www.scielo.br/pdf/pab/v41n10/a11v4110.pdf> Acesso em: 07 abr. 2020.

MELO, V. F.; SILVA, D. T.; EVALD, A.; ROCHA, P. R. R. Qualidade química e biológica do solo em diferentes sistemas de uso em ambiente de savana. Revista Agro@mbiente, v. 11, n. 2, p. 101-110, 2017. Disponível em:

<https://revista.ufrr.br/agroambiente/article/viewFile/3850/2263> Acesso em: 08 abr. 2020.

MELONNI, R; MELONNI E. G. P; ALVARENGA, M. I. N; VIEIRA, F. B. M. Avaliação da qualidade de solos sob diferentes coberturas florestais e de pastagem no sul de Minas Gerais. Revista Brasileira de Ciência do Solo. n. 32, p. 2461-2470, 2008. Disponível em: < http://www.scielo.br/pdf/rbcs/v32n6/v32n6a23.pdf> Acesso em: 08 abr. 2020.

PARRON, L. M.; GARCIA, J. R. Serviços Ambientais em Sistemas Agrícolas e Florestais do Bioma Mata Atlântica. Embrapa. Brasília-DF, 2015.

PENTEADO, S. R. Implantação do cultivo orgânico: planejamento e plantio. 2. ed. Campinas: Via Orgânica, 2012.

RECH, M.; PANSERA, M. R.; SARTORI, V. C.; RIBEIRO, R. T. S. Microbiota do solo em vinhedos agroecológico e convencional e sob vegetação nativa em Caxias do Sul, RS. Revista Brasileira de Agroecologia. v. 8, n. 3, p. 141-151, 2013. Disponível em: < https://orgprints.org/26043/1/Rech_\%20Microbiota\%20do\%20solo\%20em\%20vinhedos\%20agro ecol\%C3\%B3gico.pdf > Acesso em: 8 abr. 2020.

SANTIAGO, A.D.; ROSSETTO, R. Adubação Orgânica. 2015. Disponível em: $<$ http://www.agencia.cnptia.embrapa.br/gestor/canadeacucar/arvore/CONTAG01_37_711200516717.html>. Acesso em: 22 fev. 2020. 